\title{
Optimization of Rear Local Contacts on High Efficiency PERC Solar Cells Structures
}

\author{
Kapila Wijekoon, Fei Yan, Yi Zheng, Dapeng Wang, Hemant Mungekar, \\ Lin Zhang, and Hari Ponnekanti
}

Applied Materials, 3535 Garrett Drive, Santa Clara, CA 95054, USA

Correspondence should be addressed to Kapila Wijekoon; kapila_wijekoon@amat.com

Received 1 February 2013; Revised 11 March 2013; Accepted 14 March 2013

Academic Editor: Sudhakar Shet

Copyright (C) 2013 Kapila Wijekoon et al. This is an open access article distributed under the Creative Commons Attribution License, which permits unrestricted use, distribution, and reproduction in any medium, provided the original work is properly cited.

\begin{abstract}
A local contact formation process and integration scheme have been developed for the fabrication of rear passivated point contact solar cells. Conversion efficiency of $19.6 \%$ was achieved using $156 \times 156 \mathrm{~mm}$, pseudo square, p-type single crystalline silicon wafers. This is a significant improvement when compared to unpassivated, full area aluminum back surface field solar cells, which exhibit only $18.9 \%$ conversion efficiency on the same wafer type. The effect of rear contact formation on cell efficiency was studied as a function of contact area and contact pitch, hence the metallization fraction. Contact shape and the thickness of Al-BSF layer were found to be heavily dependent on the laser ablation pattern and contact area. Simulated cell parameters as a function of metallization showed that there is a tradeoff between open circuit voltage and fill factor gains as the metallization fraction varies. The rear surface was passivated with an $\mathrm{Al}_{2} \mathrm{O}_{3}$ layer and a $\mathrm{SiN}_{X}$ capping layer. The rear surface contact pattern was created by laser ablation and the contact geometry was optimized to obtain voids free contact filling, resulting in a uniform back surface field. The efficiency gain in rear passivated cells over the reference cells is mainly due to improved short circuit current and open circuit voltage.
\end{abstract}

\section{Introduction}

Today's industrial solar cell manufacturing process applies a full area aluminum back surface field (Al-BSF) at the rear surface of the cell. The full Al-BSF forms a good ohmic contact; however, the rear surface passivation is moderate on p-type silicon substrates $[1,2]$. Another inadequacy associated with full Al-BSF is that a significant portion of infrared light reaching the rear aluminum contact is escaping the cell without being reflected back into the bulk silicon. Both the rear surface internal reflectivity and surface passivation can be significantly improved with the passivated emitter and rear cell (PERC) architectures [3]. In the PERC approach, a passivation dielectric layer is deposited on the rear surface, which not only improves the passivation quality of the rear surface, but also increases its internal reflectivity. For the fabrication of metal contacts, local areas of the passivation layer are removed before metallization, usually screen-printed aluminum paste. The localized removal of the dielectric layer is typically accomplished using either laser ablation or chemical etching. Several different parameters, such as size of the contact opening, density of the contacts, reactivity of the aluminum paste, and thermal budget, substantially affect the formation of a robust local metal contact.

A detailed investigation of the effect of local contact geometry on the conversion efficiency of the PERC cells was performed. In this paper, the effect of the metallization factors (i.e., contact size and contact pitch) on the conversion efficiency of the PERC cells will be discussed. A thin $\mathrm{Al}_{2} \mathrm{O}_{3}$ surface passivation layer with a thicker $\mathrm{SiN}_{X}$ capping layer was used as the passivation film stack. Local contact areas in the passivation layer were opened by a laser ablation process. The metallization fraction was changed by varying the number of ablation laser pulses as well as the pitch of the contact pattern. The effect of the metallization factors on the cell parameters such as open circuit voltage $\left(V_{\mathrm{OC}}\right)$, short circuit current density $\left(J_{S C}\right)$, and fill factor $(\mathrm{FF})$ was studied in fabricated PERC cells and the results are compared with numerical calculation. 


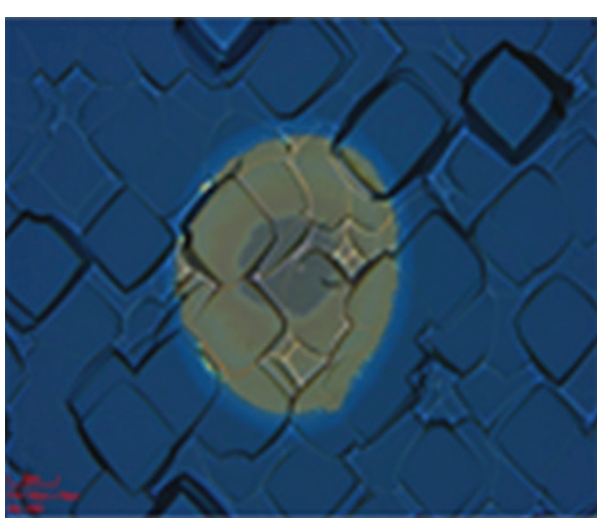

(a)

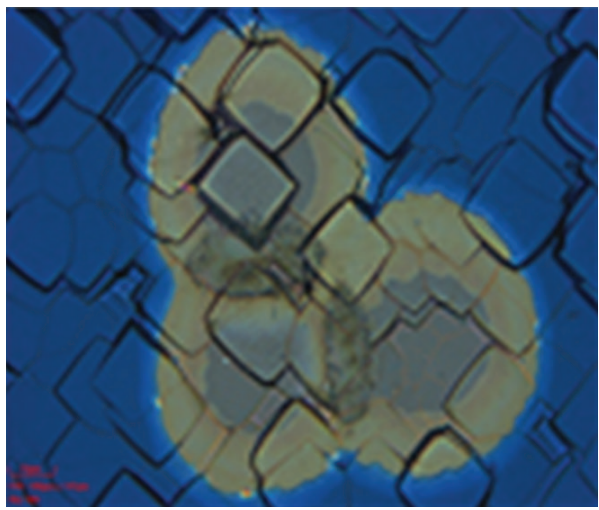

(c)

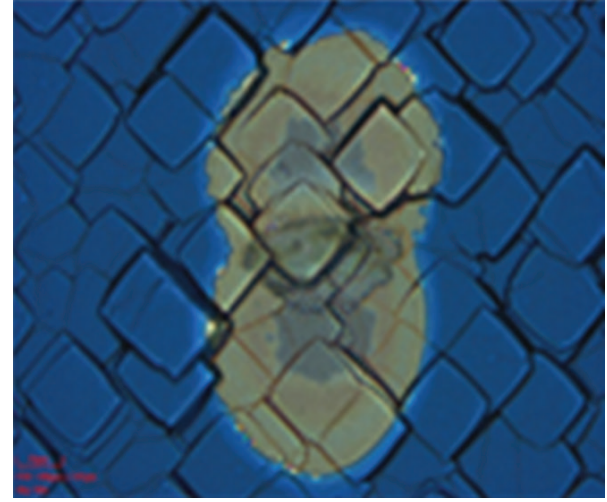

(b)

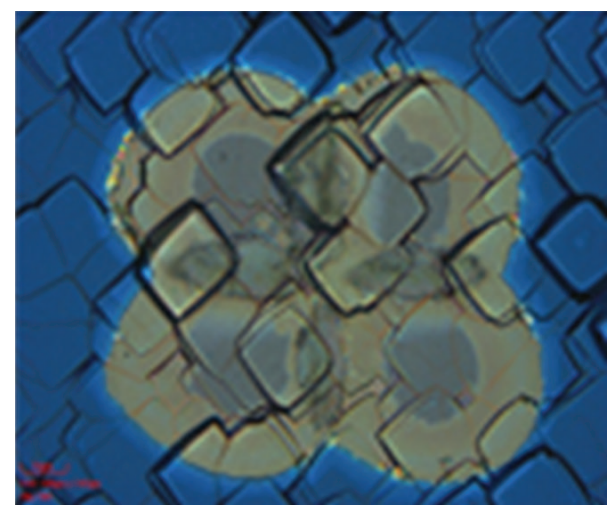

(d)

FIGURE 1: Optical microscope images of local contacts after laser ablation with one pulse (a), two pulses (b), three pulses (c), and four pulses (d).

\section{Experimental}

All wafers used in this investigation were p-type Czochralski wafers with a bulk resistivity of $1-3 \Omega \mathrm{cm}$. All wafers were subjected to an IPA free texture etching process $[4,5]$. After $\mathrm{POCl}_{3}$ diffusion, the rear emitter and texture were removed and a front $\mathrm{ARC}$ layer $\left(\mathrm{SiN}_{X}\right)$ deposited. Front ARC layers were deposited in a PECVD thin film deposition tool. The wafers were then split into two groups. The group with no rear passivation layers was used for the fabrication of reference cells (RCs). The second group was used for fabrication of PERC cells. On wafers in this group, rear passivation films were deposited and local contacts were opened with laser ablation. The rear passivation film stack consisted of a thin $\mathrm{Al}_{2} \mathrm{O}_{3}$ layer and a thicker $\mathrm{SiN}_{X}$ capping layer and was deposited using a single pass PECVD deposition system. Contact opening was performed using a high throughput laser ablation tool. The rear surface passivated wafers were subjected to several different laser ablation procedures. In one group of wafers, contact size was varied while keeping the same contact pitch. Contact size was varied with the use of multiple laser pulses. Four different ablation schemes were created using one, two, three, and four pulse sequences to make a significant change in the contact area. For the other group of wafers, the contact pitch was varied while the contact size remained constant. The same front conductor silver paste was screen printed on all wafers. Then two different aluminum pastes, one for RC and another for PERC, were screen printed and cofired on a belt furnace. The currentvoltage (IV) measurements of completed cells were made at $25^{\circ} \mathrm{C}$ under one-Sun illumination condition with a Newport Oriel solar simulator calibrated by using a reference cell certified by Fraunhofer ISE.

\section{Results and Discussion}

Figure 1 shows optical microscope images of local contacts formed after ablation of the dielectric film stack with different numbers of laser pulses. The laser ablation recipes were set up in such a way that with an increasing number of pulses, the ablation area increases. Consequently, the larger contact area increased the metallization fraction of the rear surface. It is important to make sure that the ablation process results in cleanly opened features without debris in the opened area. Postablation contact formation was investigated using SEM, EDX, and Auger microscopy. Only silicon was found to be present in the opened area after the completion via formation process, prior to metallization [6].

Figure 2 shows a SEM picture of local contact pattern after etching off the aluminum from the fabricated solar cell. As shown in Figure 2, the local contacts are very uniformly formed at the rear surface. The effect of contact opening on the passivation quality was monitored by measuring the lifetime of the minority carriers before and after laser 


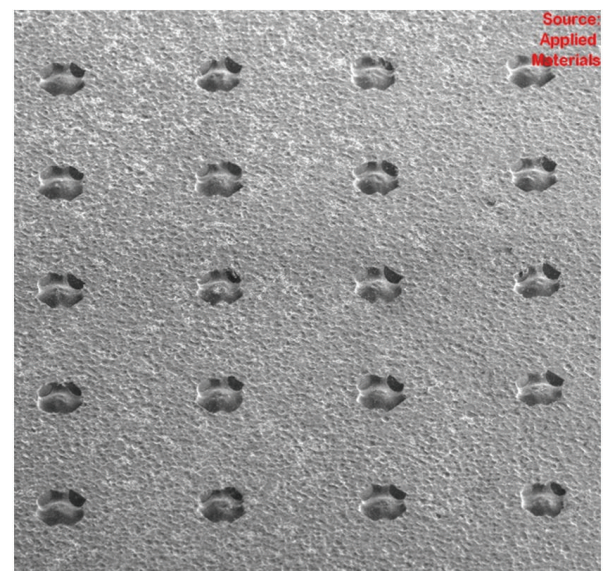

FIGURE 2: Local contact pattern fabricated using 4 laser pulses per contact point. The aluminum in the contact area has been removed with $\mathrm{HCl}$.

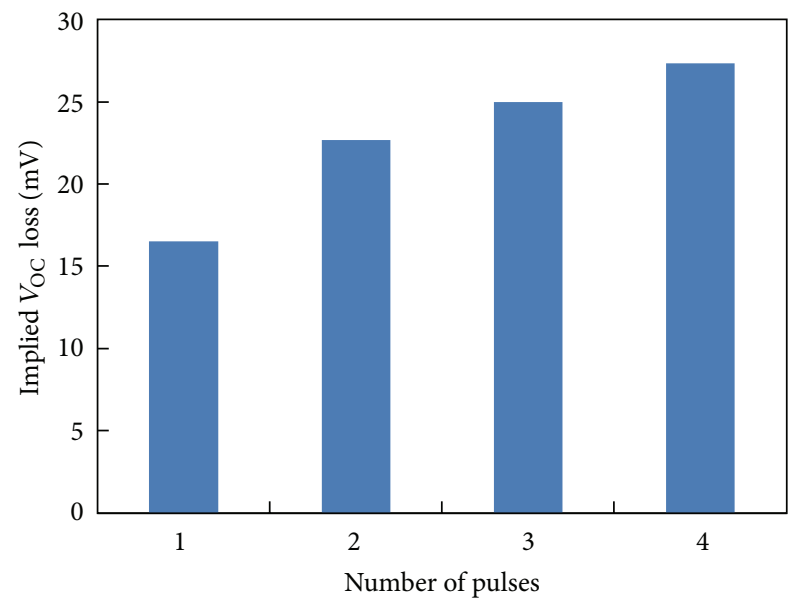

Figure 3: Loss in implied $V_{\mathrm{OC}}$ due to laser ablation as a function of number of laser pulses per contact point. Contact pitch remained constant.

ablation. All the wafers showed a decrease in lifetime after the laser ablation. Accordingly, the implied $V_{\mathrm{OC}}$ values decreased in all samples after the laser ablation. Figure 3 shows the loss in implied $V_{\mathrm{OC}}$ as a function of number of laser pulses. The loss in implied $V_{\mathrm{OC}}$ increased as the number of laser pulses increased. It is clear that an increasing number of laser pulses lead to a larger ablation area of contact, as shown in Figure 1. Therefore, the fraction of the passivation film removed from the surface increased as the number of laser pulses increased, leading to an increased loss in passivation quality, hence the implied $V_{\mathrm{OC}}$. A similar trend in implied $V_{\mathrm{OC}}$ loss was observed when the contact pitch was varied (Figure 4).

When the number of pulses remained constant but contact pitch was varied, the highest implied $V_{\text {OC }}$ loss was observed for the smallest pitch and smallest $V_{\mathrm{OC}}$ loss was observed for the highest pitch. This observation again can be explained in terms of the fraction of passivation layer removed. When the contact pitch was smaller, contact density was higher and the fraction of passivation layer removed during ablation was higher. Therefore, the passivation effect

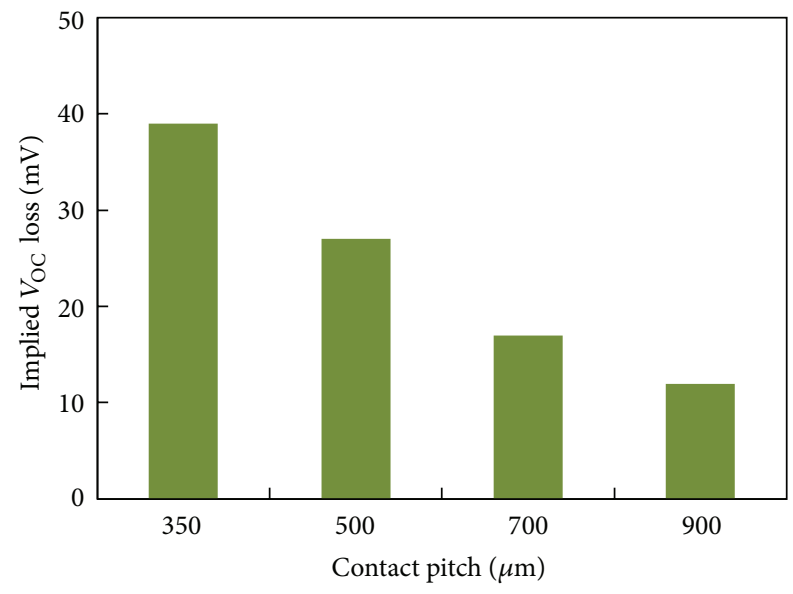

FIgURE 4: Loss in implied $V_{\text {OC }}$ values due to laser ablation as a function of pitch of the local contact. The number of laser pulses per contact remained constant.

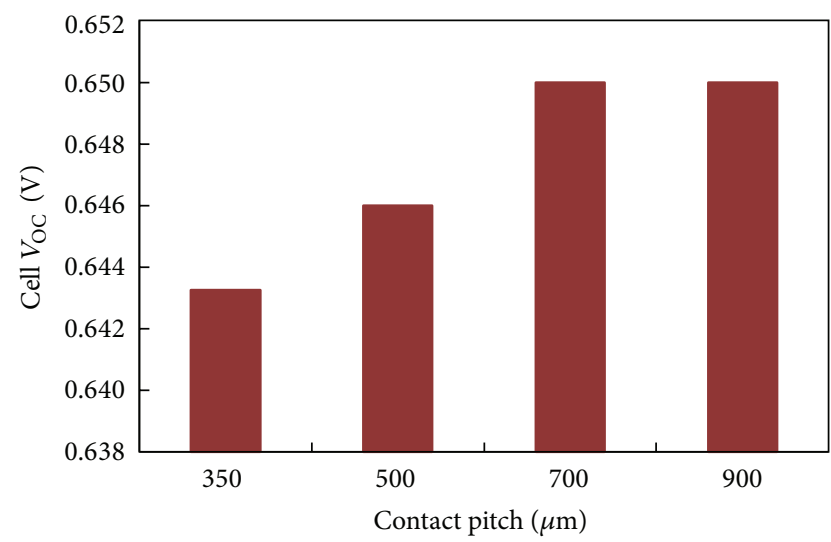

Figure 5: $V_{\text {OC }}$ values of PERC cells as function of contact pitch.

was reduced. This led to a larger drop in effective lifetime and implied $V_{\text {OC. }}$. This effect was clearly reflected on PERC cell $V_{\mathrm{OC}}$ values shown in Figure 5.

Figure 5 shows $V_{\mathrm{OC}}$ values of PERC cells fabricated by varying the contact pitch while keeping the contact size constant. When the pitch was higher, the fraction of the passivation film removed was smaller and as a consequence, the metallization fraction was smaller. The $V_{\mathrm{OC}}$ values of the cells gradually increased with the increased pitch and seemed to level off when the pitch was about $700 \mu \mathrm{m}$. The contact pitch of $700 \mu \mathrm{m}$ corresponds approximately to a metallization fraction of $2.3 \%$. Further reduction in metallization factor down to $1.4 \%$ ( $900 \mu \mathrm{m}$ pitch) did not seem to improve the cell $V_{\mathrm{OC}}$ value. Nevertheless, when the metallization fraction is $1.4 \%$, the corresponding implied $V_{\mathrm{OC}}$ loss (before metallization) was smaller. However, these improvements were not realized in cell efficiencies (Figure 6) due to degrading fill factor (Figure 7) values.

As indicated previously, as the area of ablated contact increased, losses in the implied $V_{\mathrm{OC}}$ increased (Figure 3). The $V_{\mathrm{OC}}$ values of the PERC cells with different contact area are shown in Figure 8. When four laser pulses were used, the metallization fraction corresponded to $4.4 \%$. Accordingly, by 


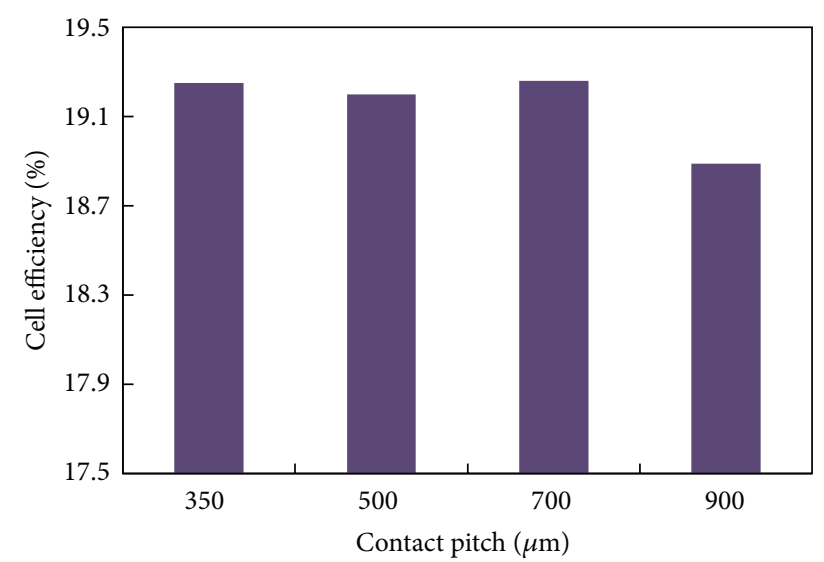

FIgURE 6: Conversion efficiencies of PERC cells as function of contact pitch.

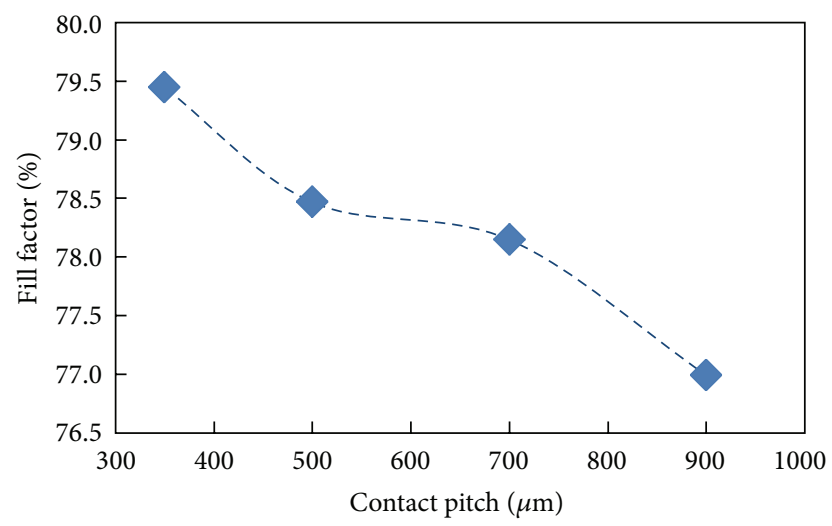

FIGURE 7: FF values of PERC cells as a function of contact pitch.

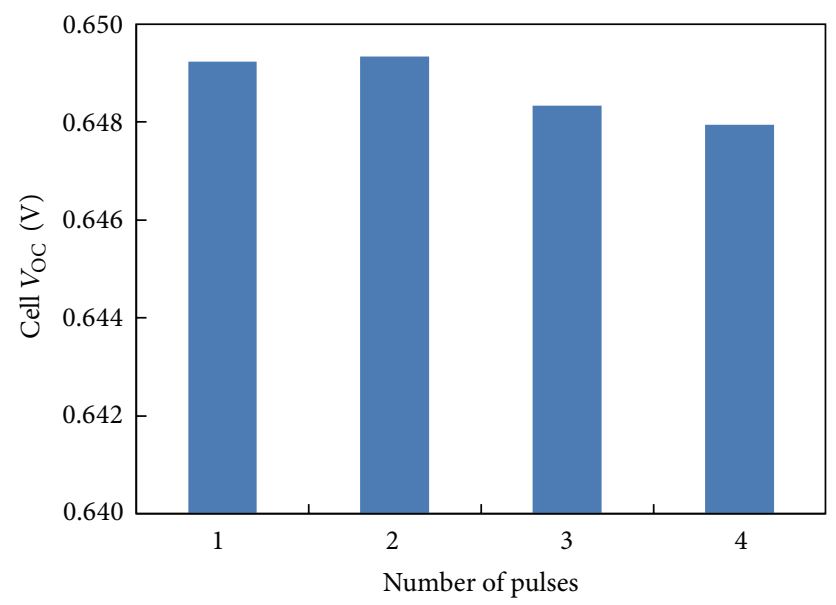

FIgURE 8: The $V_{\mathrm{OC}}$ values of PERC cells as function of number of laser pulses (contact area).

neglecting the change in area due to pulse overlap, single pulse ablation results in a metallization factor of $1.1 \%$. As the metallization fraction increased, cell $V_{\mathrm{OC}}$ decreased gradually. However, again the $V_{\mathrm{OC}}$ improvement in contact with

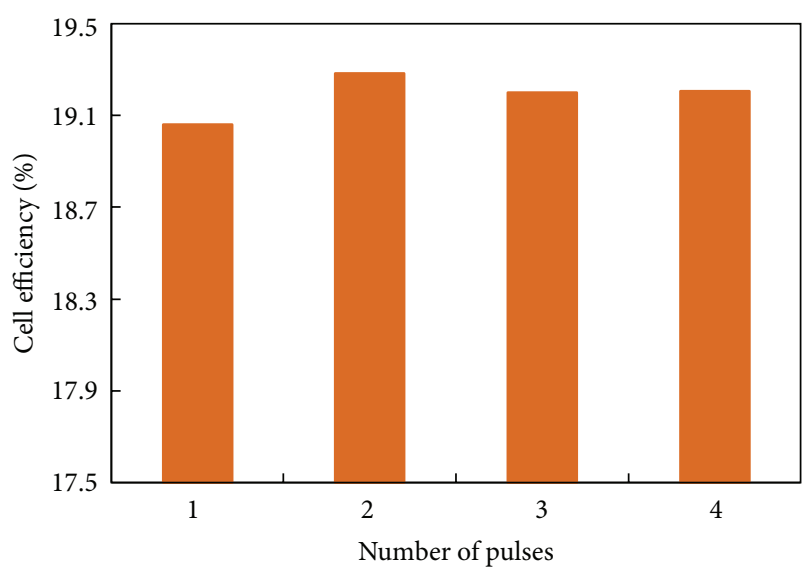

FIgURE 9: The conversion efficiencies of PERC cells as function of number of laser pulses (contact area).

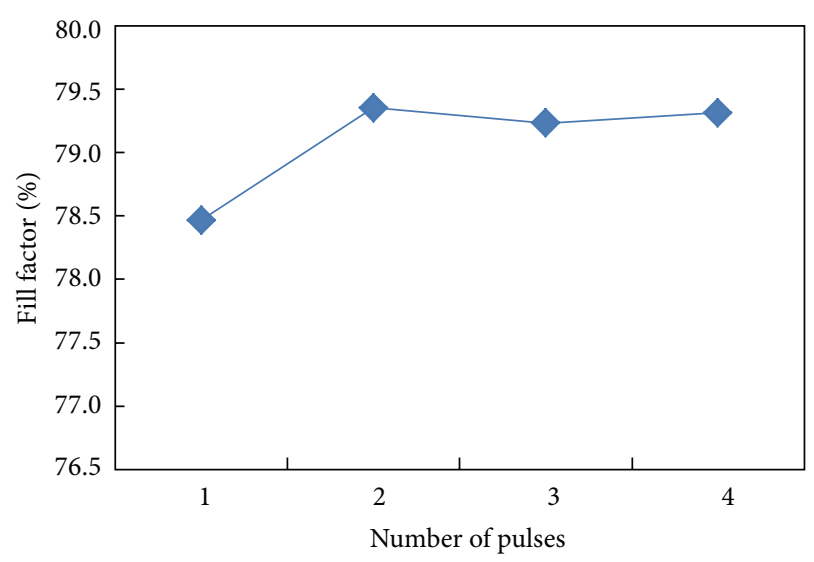

FIgure 10: Fill factor values of PERC cells as a function of the number of laser pulses (contact size).

smaller contact area, hence smaller metallization fraction, is not reflected in cell efficiencies, as shown in Figure 9.

As shown in Figure 9, single pulse ablation (metallization fraction of 1.1\%) resulted in lower conversion efficiencies in PERC cells compared to all other three ablation schemes. Again, the main factor contributing to lower conversion efficiency in PERC cells with smaller metallization fraction was found to be the low FF as shown in Figure 10. The data shown in Figure 10 cleary shows that cells with smaller contact size (metallization fraction of 1.1\%) resulted in lower FF values. All other cases where metallization fractions were $2.2 \%, 3.3 \%$, and $4.4 \%$ (resp., 2,3 , and 4 pulse ablation) yielded almost identical FF.

In order to gain some insight into the passivation quality of local contacts, a numerical simulation was carried out by using the theoretical formula derived by Fischer [7]. According to Fisher formula the effective rear surface recombination velocity $\left(S_{\text {eff }}\right)$ can be written as

$$
S_{\text {eff }}=\left(\frac{R_{S}-\rho W}{\rho D}+\frac{1}{f S_{\text {cont }}}\right)^{-1}+\frac{S_{\text {pass }}}{1-f}
$$




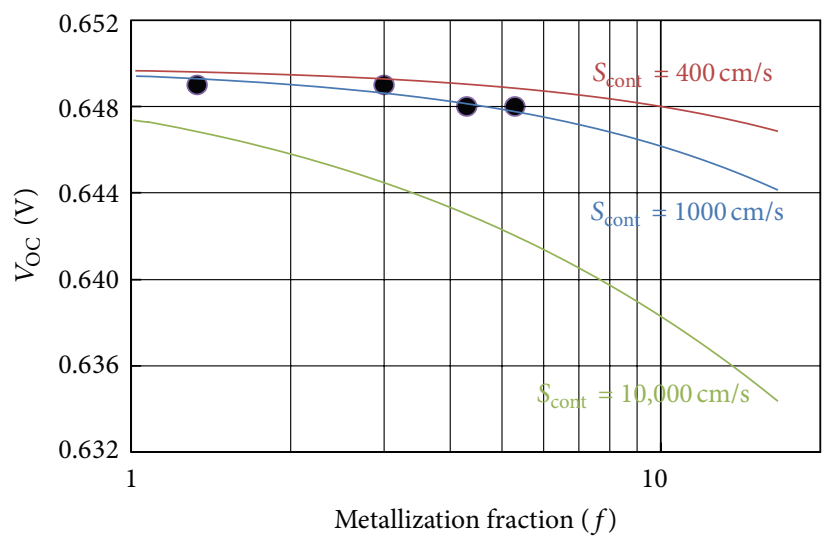

FIgURE 11: Simulated $V_{\mathrm{OC}}$ as a function of metallization fraction. The variation in $V_{\mathrm{OC}}$ for three different $S_{\text {cont }}$ is shown. Scattered data points are the experimental values.

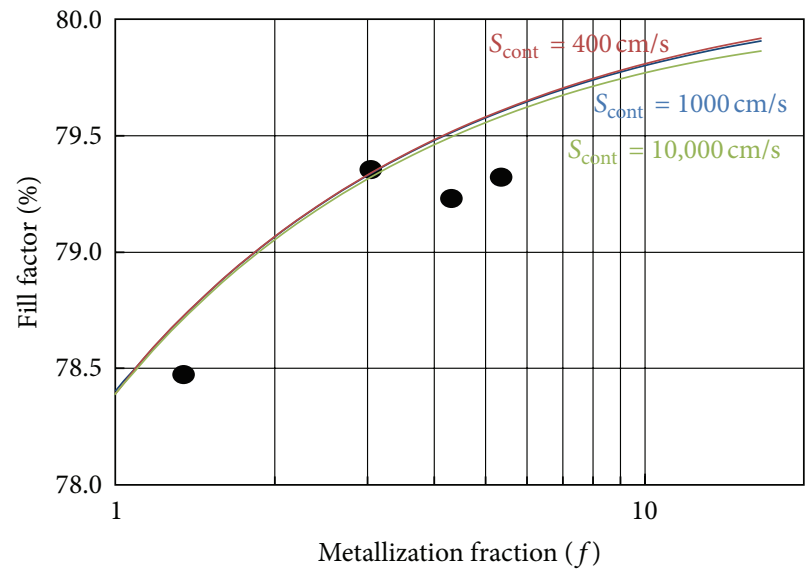

FIGURE 12: Simulated FF as function of metallization fraction. The variation of FF for three different $S_{\text {cont }}$ is shown. Scattered data points are the experimental values.

where $S_{\text {pass }}$ is the surface recombination velocity in passivated area, and $S_{\text {cont }}$ is the recombination velocity at the contact, $W$ is the substrate thickness, $f$ is the metallization fraction, $\rho$ is the base resistivity, $D$ is the carrier diffusion coefficient, and $R_{S}$ is the series resistance of the base. The value of $R_{S}$ depends on the contact layout and can be expressed as [8]

$$
R_{S}=p^{2} \frac{\rho}{2 \pi r} \arctan \left(\frac{2 W}{r}\right)+\rho W\left\{1-\exp \left(-\frac{W}{p}\right)\right\} \text {. }
$$

Here $r$ is the radius of the contact and $p$ is the contact pitch. Once $R_{S}$ and $S_{\text {eff }}$ values were calculated, those values together with averaged rear surface internal reflectivity value were used as input to a calibrated device model set up in PC1D simulating program [9]. This model was used to simulate the device performance for different contact size and contact pitch combinations. Passivation quality was simulated for three different $S_{\text {cont }}$ values, namely, $400 \mathrm{~cm} / \mathrm{s}$, $1000 \mathrm{~cm} / \mathrm{s}$, and $10000 \mathrm{~cm} / \mathrm{s}$. The simulation of $V_{\mathrm{OC}}, \mathrm{FF}$ values, and a comparison of corresponding experimental results are presented in Figures 11 and 12, respectively.

Simulation results presented in Figures 11 and 12 show the tradeoff between $V_{\mathrm{OC}}$ and FF. The FF loss at smaller $f$ values is mainly due to resistive losses. The $V_{\mathrm{OC}}$, as well as $J_{\mathrm{SC}}$, losses at relatively larger $f$ values are due to higher recombination losses $\left(S_{\text {eff }}\right)$ and lower internal reflectivity values. When the metallization fraction $(f)$ is higher, the internal reflectivity is smaller. The simulated results predicted that the highest conversion efficiency would be achieved when the metallization fraction $(f)$ is in the range of $2-4 \%$.

In order to study the geometry of the contacts that were fabricated with various ablation laser pulses, aluminum paste was removed from PERC cells by dissolving it in a hydrochloric acid solution. The local contact areas were then studied with scanning electron microscopy (SEM) and confocal optical microscopy [10]. Figure 13 shows SEM images of various local contacts after aluminum removal. It is well known that, during the contact firing process, silicon dissolves into the aluminum matrix from beneath the contact area [11-14]. In the case of local contacts, only silicon underneath the opened contact areas is available for this process. Therefore, the silicon concentration is higher in liquid aluminum above the contact points compared to other areas. This concentration gradient will result in a diffusion of silicon away from contact site. As a result, recesses, which in some cases can be as deep as $30-40 \mu \mathrm{m}$, formed in the bulk silicon, as shown in 


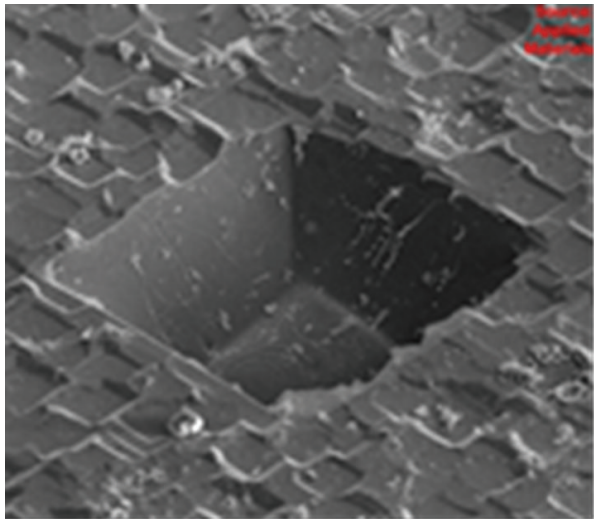

(a)

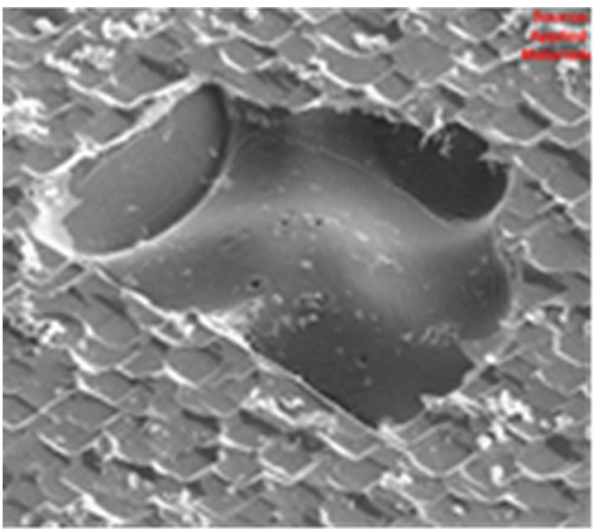

(c)

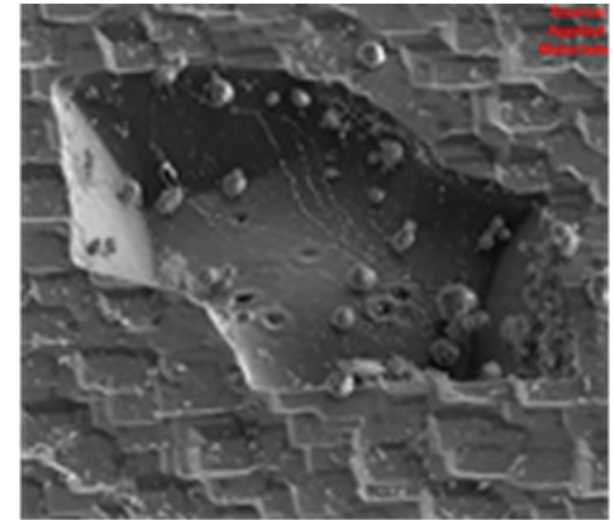

(b)

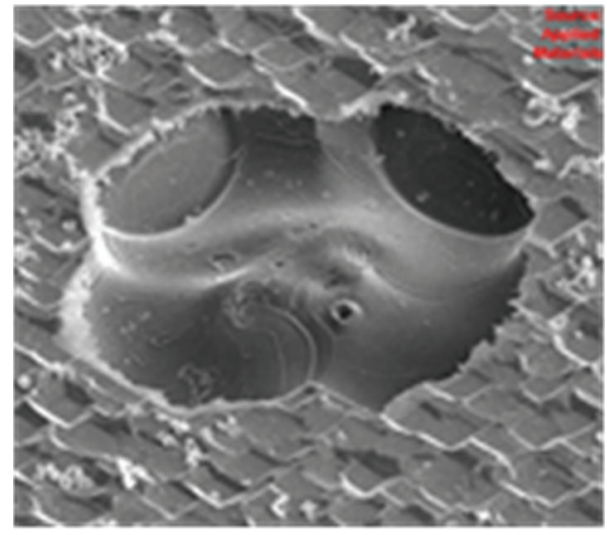

(d)

Figure 13: SEM images of local contacts after aluminum removal: one pulse (a), two pulses (b), three pulses (c), and four pulses (d).

Figure 13. These recesses show the characteristic shape of truncated pyramids. These truncated pyramidal structures are formed due to preferential dissolution of silicon along the (100) planes.

The aluminum etched back contacts were studied further with confocal microscopy and the results are shown in Figure 14. In many situations, it was found that the depth at the edge of the recess was larger than at the center.

The depth of the feature shown in Figure 14 was found to be about $23 \mu \mathrm{m}$ at the center and about $42 \mu \mathrm{m}$ at the edge. The angle between the side wall and bottom is about $53^{\circ}$, which indicates preferential dissolution of silicon along (100) planes during contact formation. In the case of an isotropic etching of silicon substrates, random pyramids are formed and the angle was found to be $54.7^{\circ}$. It was found that the depth of the recess decreased as the area of the contact increased. With smaller open contacts the area exposed to aluminum paste is smaller. For a given peak temperature, silicon dissolution into liquid aluminum takes place until the saturation limits are reached. Therefore, in the case of smaller size contacts, silicon dissolution runs deeper into the bulk silicon. During the cooling cycle, silicon re-crystallizes, creating an aluminum doped $\mathrm{p}^{+}$(Al-BSF) layer. After further cooling, eutectic temperature is reached and the remaining $\mathrm{Al}-\mathrm{Si}$ liquid phase solidifies, completing

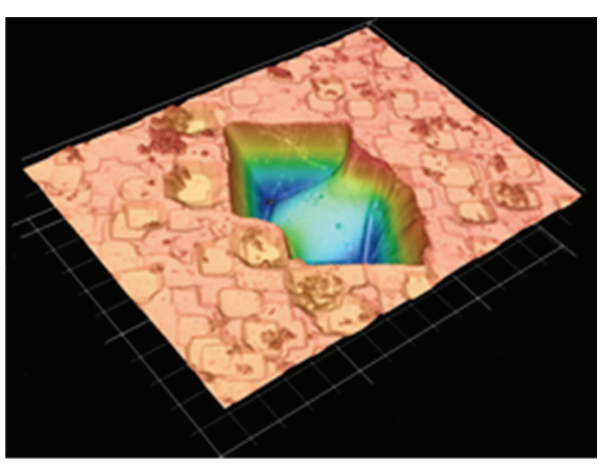

(a)

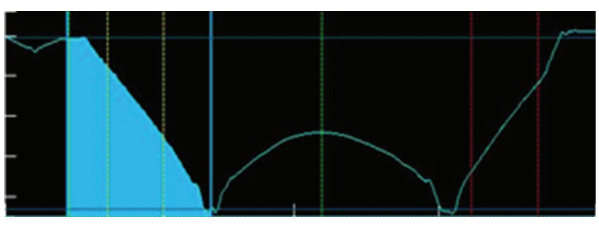

(b)

FIGURE 14: Confocal microscope image of local contacts after aluminum removal (a) and depth profile of the recess (b). In this case two laser pulses were used for ablation, as shown in Figures 1 and 13. 


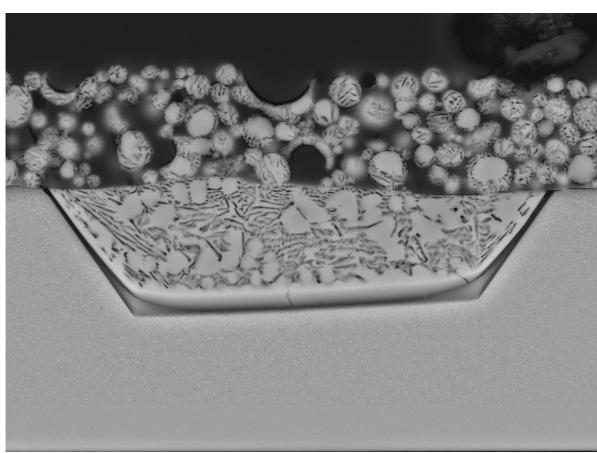

(a)

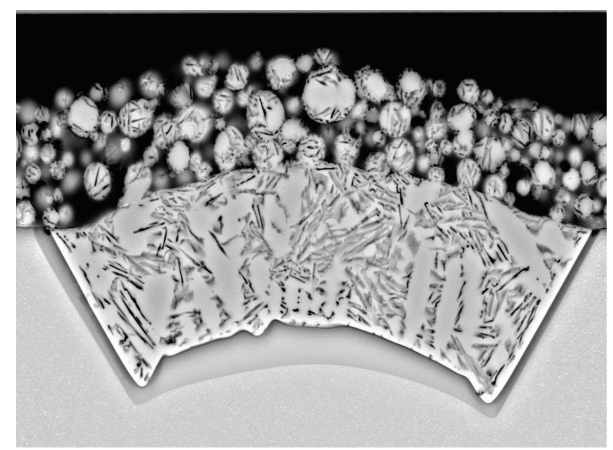

(b)

FIGURE 15: Cross sectional SEM images of fully alloyed contacts. (a) Single pulse ablation (thickness of BSF layer $\sim 1.25 \mu \mathrm{m}$ ), (b) three pulse ablation (thickness of BSF layer $\sim 5.9 \mu \mathrm{m}$ ).

the alloying process. Out-diffusion of silicon, away from the contact, will deplete the silicon concentration, which can contribute to BSF formation. In the case of smaller contacts, the extent of out-diffusion of silicon is larger, relative to larger contacts. This will result in relatively thin Al-BSF layers in smaller contacts. However, it should be noted that for a given contact geometry, these difficulties can be overcome with modifications to paste composition and optimized firing conditions [6].

Cross section SEM images of alloyed contacts fabricated with different numbers of ablation pulses are shown in Figure 15. These SEM images clearly show Al-alloyed contact with the presence of a uniform Al-BSF layers. However, as the area of the contact increased the thickness of the Al-BSF layer increased. As measured with cross sectional SEM, the thicknesses of BSF layers varied from $1.25 \mu \mathrm{m}, 2.45 \mu \mathrm{m}$, and $5.9 \mu \mathrm{m}$ to $6.1 \mu \mathrm{m}$ for contacts ablated with $1,2,3$, and 4 laser pulses, respectively.

Based on the above findings, the contact size and the contact pitch were optimized for PERC cell development. It should be noted that all the preliminary experimental data presented in Figure 1 through Figure 10 contain the results of an average of five wafers for each data point. Once optimized process conditions were established, PERC cells and reference cells were fabricated with a larger sample size. Wafers from the same lot were divided into two groups and one group was used for the PERC cells and the other was used for fabrication of reference cells. Each group contained 12 wafers. The results of these two wafer groups are summarized in Table 1. The champion PERC cell fabricated in this study resulted in conversion efficiency of $19.6 \%$ compared to the champion RC of $18.9 \%$. The gain in the PERC cell was due to improved $J_{\mathrm{SC}}$ and $V_{\mathrm{OC}}$. It should be noted that, during the rear emitter removal step, the backside of the wafers was polished and texturization was removed. Therefore, both types of cells (PERC and RC) have identical rear side reflections after parasitic emitter removal. The gain in conversion efficiency in the champion PERC cell over the champion RC cell was $0.7 \%$, as shown in Table 1 . The average conversion efficiency gain was $0.6 \%$ over RC. The average $J_{S C}$ gain in PERC cells was more than $1 \mathrm{~mA} / \mathrm{cm}^{2}$ compared to the reference cells. The PERC cells also show significantly improved $V_{\text {OC }}$ over the RC.
TABLE 1: Comparison of solar cell performance for PERC and RC cells.

\begin{tabular}{lcccc}
\hline Cell & $J_{\text {SC }}\left(\mathrm{mA} / \mathrm{cm}^{2}\right)$ & $V_{\mathrm{OC}}(\mathrm{mV})$ & $\mathrm{FF}(\%)$ & Eta $(\%)$ \\
\hline Best RC & 37.3 & 639 & 79.4 & 18.90 \\
Best PERC & 38.5 & 648 & 78.7 & 19.62 \\
Average RC & 37.11 & 638 & 79.52 & 18.82 \\
Average PERC & 38.36 & 646 & 78.69 & 19.49 \\
\hline
\end{tabular}

\section{Summary}

Local contact formation in PERC cells was studied in detail with respect to contact area and pitch, hence the metallization fraction. With the optimized contact geometry, a process flow for manufacturing PERC solar cells yielding 19.6\% conversion efficiency was developed for industrial applications. The efficiency gain of PERC cells over conventional solar cells was $0.7 \%$. The efficiency gain in the PERC cells was mainly due to improved short circuit current and open circuit voltage.

\section{Acknowledgments}

The authors thank Andie Chan, Kalyan Rapolu, Prabhat Kumar, Manoj Vellaikal, Xuesong Liu, Damanjot Kochhar, Michael Stewart, and Jeff Franklin for their contributions to this work.

\section{References}

[1] S. Gatz, T. Dullweber, and R. Brendel, "Evaluation of serious resistance losses in screen-printed solar cells with local rear contacts," IEEE Journal of Photovoltaics, vol. 1, pp. 37-42, 2011.

[2] T. Lauermann, T. Lüder, S. Scholz, B. Raabe, G. Hahn, and B. Terheiden, "Enabling dielectric rear side passivation for industrial mass production by developing lean printing-based solar cell processes," in Proceedings of the 35th IEEE Photovoltaic Specialists Conference (PVSC '10), pp. 28-33, Honolulu, Hawaii, USA, June 2010.

[3] A. W. Blakers, A. Wang, A. M. Milne, J. Zhao, and M. A. Green, "22.8\% efficient silicon solar cell," Applied Physics Letters, vol. 55, no. 13, pp. 1363-1365, 1989. 
[4] K. Wijekoon, T. Weidman, S. Paak, and K. MacWilliams, "Production ready noval texture etching process for fabrication of single crystalline silicon solar cells," in Proceedings of the 35th IEEE Photovoltaic Specialists Conference (PVSC '10), pp. 36353641, Honolulu, Hawaii, USA, June 2010.

[5] K. Wijekoon, P. Kumar, D. Tanner, H. Ponnekanti, and C. Gay, "Effect of additive and etchant concentration in surface morphology of mono-crystalline silicon solar cells textured with non-alcoholic chemical formulations," in Proceedings of the 26th European Photovoltaic Solar Energy Conference and Exhibition (EU PVSEC '11), pp. 2015-2019, Hamburg, Germany, September 2011.

[6] K. Wijekoon, H. Mungekar, M. Stewart et al., "Development of high efficiency mono-crystalline silicon solar cells: optimization of rear local contacts formation on dielectrically passivated surfaces," in Proceedings of the 38th IEEE Photovoltaic Specialists Conference (PVSC '12), pp. 28-33, June 2012.

[7] B. Fischer, Loss analysis of crystalline silicon solar cells using photoconductance and quantum efficiency measurements [Ph.D. dissertation], Universität Konstanz, Konstanz, Germany, 2003.

[8] R. H. Cox and H. Strack, "Ohmic contacts for GaAs devices," Solid State Electronics, vol. 10, no. 12, pp. 1213-1218, 1967.

[9] P. Basore and D. Clugston, PCld Version 5. 1 for Windows, UNSW, Sydney, Australia, 1997.

[10] M. Rauer, C. Schmiga, K. Ruhle, R. Woehl, M. Hermle, and S. Glunz, "Investigation of aluminum-alloyed local contacts for rear surface-passivated silicon solar cells," IEEE Journal of Photovoltaics, vol. 1, no. 1, pp. 22-28, 2011.

[11] E. Urrejola, K. Peter, H. Plagwitz, and G. Schubert:, "Silicon diffusion in aluminum for rear passivated solar cells," Applied Physics Letters, vol. 98, no. 15, Article ID 153508, 3 pages, 2011.

[12] E. Urrejola, K. Peter, H. Plagwitz, and G. Schubert, "Al-Si alloy formation in narrow $p$-type Si contact areas for rear passivated solar cells," Journal of Applied Physics, vol. 107, no. 12, Article ID 124516, 2010.

[13] T. Lauermann, A. Zuschlag, S. Scholz, G. Hahn, and B. Terheiden, "The influence of contact geometry and sub contact passivation on the performance of screen printed $\mathrm{Al} 2 \mathrm{O} 3$ passivated solar cells," in Proceedings of the 26th European Photovoltaic Solar Energy Conference and Exhibition (EU PVSEC '11), pp. 1137-1143, Hamburg, Germany, September 2011.

[14] J. Krause, R. Woehl, and D. Biro, "Analysis of local Al-P+-layers for solar cells processed by small screen-printed structures," in Proceedings of the 25th European Photovoltaic Solar Energy Conference and Exhibition (EU PVSEC '10), pp. 1899-1904, Valencia, Spain, September 2010. 

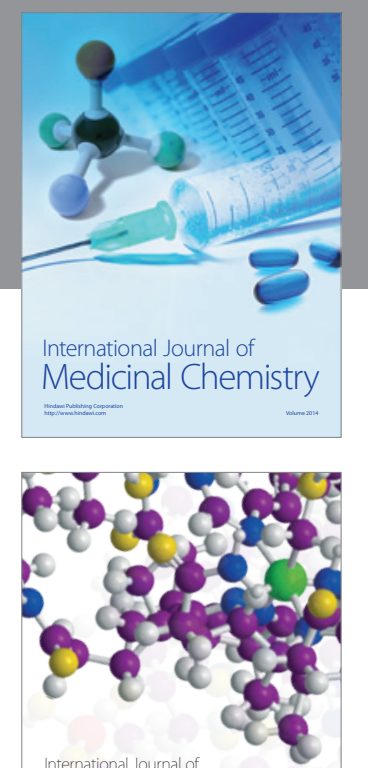

\section{Carbohydrate} Chemistry

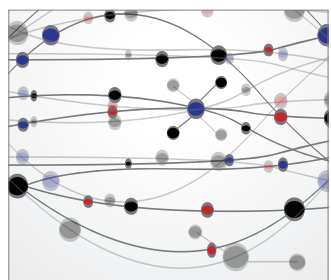

The Scientific World Journal
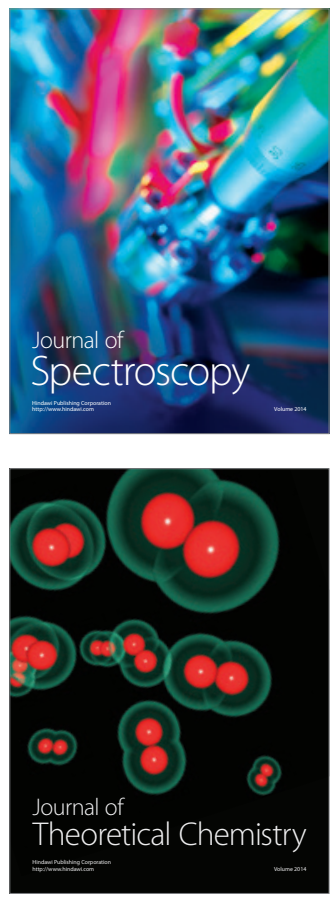
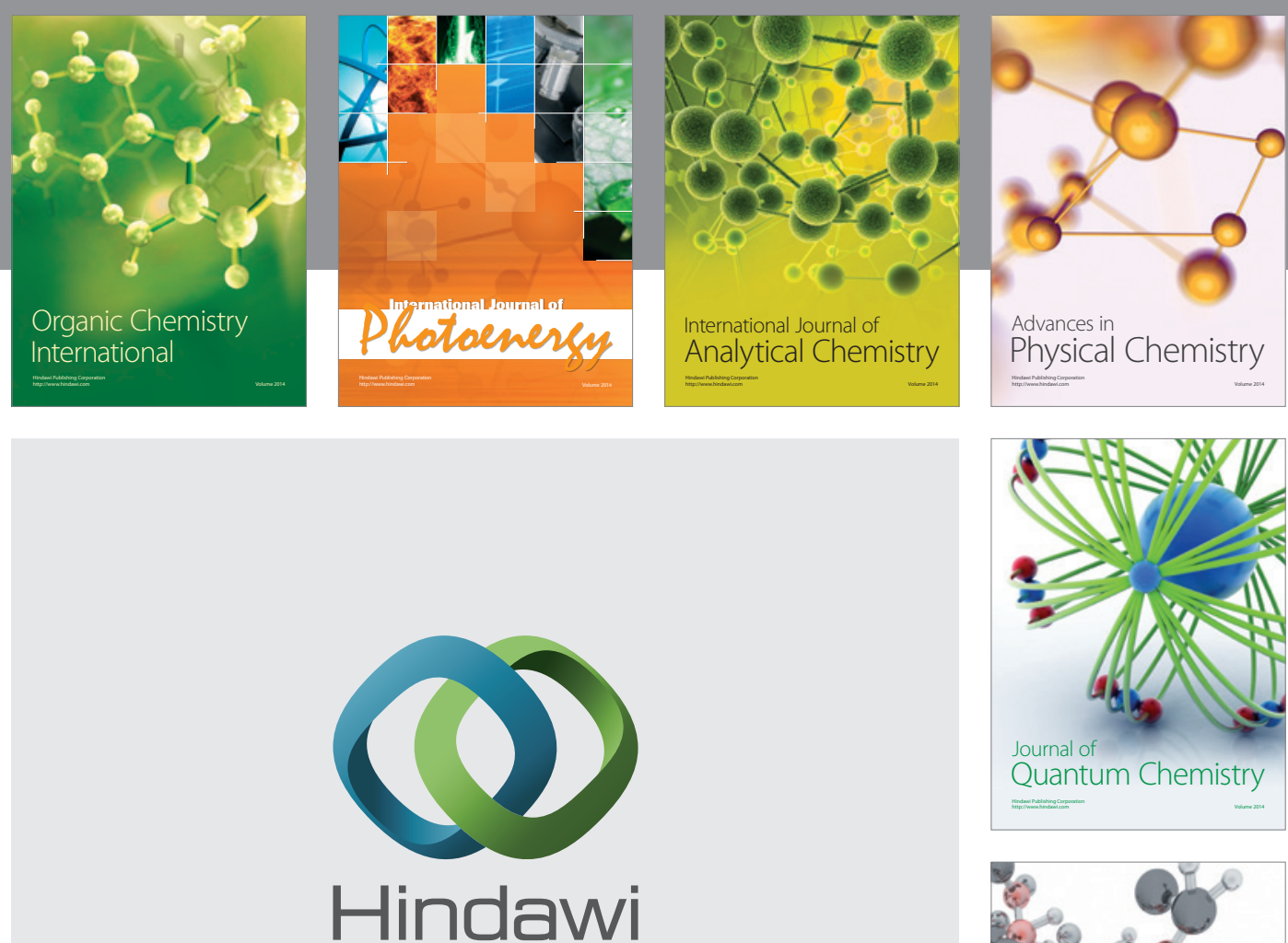

Submit your manuscripts at

http://www.hindawi.com

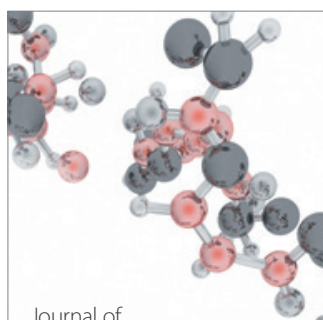

Analytical Methods

in Chemistry

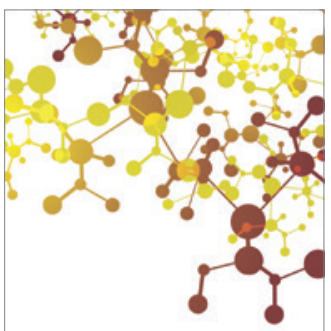

Journal of

Applied Chemistry

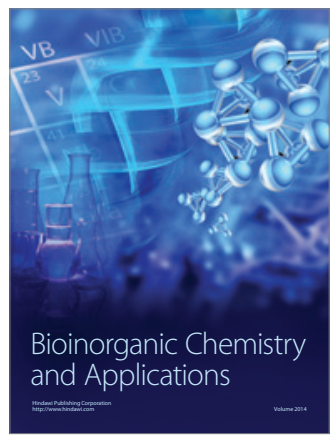

Inorganic Chemistry
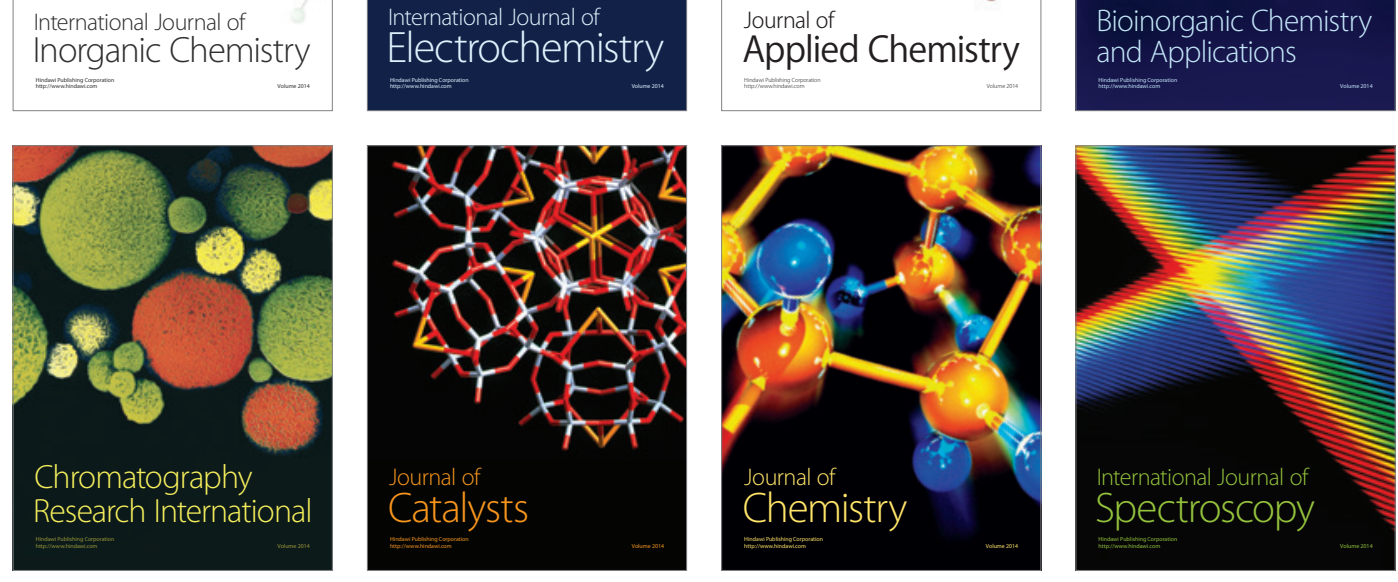